\title{
In vitro characterization of pralidoxime
} transport and acetylcholinesterase reactivation across MDCK cells and stem cell-derived human brain microvascular endothelial cells (BC1-hBMECs)

\author{
Erin Gallagher ${ }^{1,2}$, II Minn ${ }^{3}$, Janice E. Chambers ${ }^{4}$ and Peter C. Searson ${ }^{1,2^{*}}$
}

\begin{abstract}
Background: Current therapies for organophosphate poisoning involve administration of oximes, such as pralidoxime (2-PAM), that reactivate the enzyme acetylcholinesterase. Studies in animal models have shown a low concentration in the brain following systemic injection.

Methods: To assess 2-PAM transport, we studied transwell permeability in three Madin-Darby canine kidney (MDCKII) cell lines and stem cell-derived human brain microvascular endothelial cells (BC1-hBMECs). To determine whether 2-PAM is a substrate for common brain efflux pumps, experiments were performed in the MDCKII-MDR1 cell line, transfected to overexpress the P-gp efflux pump, and the MDCKII-FLuc-ABCG2 cell line, transfected to overexpress the BCRP efflux pump. To determine how transcellular transport influences enzyme reactivation, we developed a modified transwell assay where the inhibited acetylcholinesterase enzyme, substrate, and reporter are introduced into the basolateral chamber. Enzymatic activity was inhibited using paraoxon and parathion.

Results: The permeability of 2-PAM is about $2 \times 10^{-6} \mathrm{~cm} \mathrm{~s}^{-1}$ in MDCK cells and about $1 \times 10^{-6} \mathrm{~cm} \mathrm{~s}^{-1}$ in BC1hBMECs. Permeability is not influenced by pre-treatment with atropine. In addition, 2-PAM is not a substrate for the P-gp or BCRP efflux pumps.

Conclusions: The low permeability explains poor brain penetration of 2-PAM and therefore the slow enzyme reactivation. This elucidates one of the reasons for the necessity of sustained intravascular (IV) infusion in response to organophosphate poisoning.
\end{abstract}

\section{Background}

The blood-brain barrier (BBB) is a dynamic system responsible for maintaining homeostasis by regulating the chemical environment, immune cell transport, and the entry of toxins into the CNS [1-3]. Neurotoxins are microorganisms, viruses, bacterial toxins, and chemicals that disrupt neurological function [2, 4].

\footnotetext{
*Correspondence: searson@jhu.edu

1 Institute for Nanobiotechnology Johns Hopkins University,

3400 North Charles Street, Baltimore, MD 21218, USA

Full list of author information is available at the end of the article
}

Organophosphates (OPs) are a class of chemical neurotoxicants comprised of a central phosphate surrounded by electronegative atoms, such as oxygen and sulfur. While widely used as insecticides, nerve agents such as sarin and VX, are also organophosphates [5]. In the brain and body, organophosphates persistently bind to the active site of acetylcholinesterase, blocking breakdown of the neurotransmitter acetylcholine [6,7].

Organophosphate poisoning is usually treated with oximes, such as pralidoxime (2-PAM), that reactivate acetylcholinesterase [7]. The FDA protocol for organophosphate poisoning involves immediate intramuscular 
(IM) injection followed by intravascular (IV) administration [6, 8]. IM injection of 2-PAM is usually co-administered with atropine and/or diazepam. Typical IV dosing of 2-PAM, depending on symptoms and exposure pathway, involves administration of $1 \mathrm{~g}$ in $100 \mathrm{~mL}^{-1}$ saline over 15-30 $\mathrm{min}$ followed by continuous infusion of $500 \mathrm{mg} \mathrm{h}^{-1}$ (about $700 \mu \mathrm{M}$ in blood) [6, 7].

2-PAM is an ionic molecule and hence the permeability across the blood-brain barrier has been assumed to be very low $[9,10]$. Clinical trials have shown that 2-PAM is rapidly cleared from the body $[11,12]$, highlighting the need for continuous infusion to maintain a therapeutic dose [11, 13-15]. Based on animal studies, the minimum effective concentration in blood is reported to be around $4 \mathrm{mg} \mathrm{L}^{-1}$ (about $30 \mu \mathrm{M}$ ) $[9,15]$.

Therefore, to assess transport into the brain we studied permeability of 2-PAM in four cell lines: MDCKII, MDCKII-MDR1, MDCKII-FLuc-ABCG2, and BC1hBMECs. Madin-Darby canine kidney epithelial cells (MDCKs) are widely used for in vitro assessment of brain penetration and the permeability values for a wide range of solutes have been reported [16]. The MDCKII-MDR1 cell line is transfected to express the human P-gp efflux pump, and the MDCKII-FLuc-ABCG2 line is transfected to overexpress BCRP efflux pump. Human brain microvascular endothelial cells (BC1-hBMECs) are derived from humaninduced pluripotent stem cells (hiPSCs) [17-19].

\section{Materials \\ Cell lines}

MDCKII and MDCKII-MDR1 cells were obtained from the Netherlands Cancer Institute (NKI) [20]. Following NKI's protocol, cells were cultured in DMEM (High Glucose, GlutaMAX) with 10 \% Fetal Bovine Serum (FBS, ATCC, Manassas, VA, USA), and $1 \%$ penicillinstreptomycin (ATCC). MDCKII/ABCG2 cells expressing $A B C G 2 / B C R P$ were provided by the Pomper Group (JHU). MDCKII cells were transfected with pGL4.16 [luc2cp/Hygro] (Promega, Madison, WI, USA) [21, 22]. Cells were maintained in MEM-L-glutamine (Life Tech, Carlsbad, CA, USA), 10 \% FBS HI, $1 \mathrm{mg} \mathrm{mL}^{-1}$ G418 (Geneticin, Life Tech), and $100 \mu \mathrm{g} \mathrm{mL}{ }^{-1}$ Hygromycin B (Life Tech) [22].

Human brain microvascular endothelial cells (BC1hBMECs) were derived from iPSCs, based on a protocol reported by Lippmann et al. [17, 18]. Briefly, BC1 iPSCs [23] were cultured for 4 days in TeSR-E8 Basal Medium (05940, Stem Cell Technologies, Vancouver, BC, Canada) on growth factor-reduced Matrigel, $40 \mu \mathrm{g} \mathrm{mL}{ }^{-1}$ (354230, Fisher Scientific, Pittsburgh, PA, USA) [19]. Once cells formed substantial colonies, they were placed in UM/F- unconditioned media (DMEM/F12, $20 \%$ KOSR, $0.5 \%$ L-glutamine, $1 \%$ NEAA, $0.836 \mu \mathrm{M}$
Beta-Mercaptoethanol) for 6 days. For the final 2 days of differentiation, the cells were placed in endothelial cell serum-free media (EC, $1 \%$ human platelet poor-derived serum, $20 \mathrm{ng} \mathrm{mL}^{-1} \mathrm{bFGF}$ ) with $10 \mu \mathrm{M}$ all trans retinoic acid (Sigma, St. Louis, MO, USA) to promote preferential growth of the BC1-hBMECs. The cells were then sub-cultured onto the transwell supports coated with collagen IV (100 $\mu \mathrm{g} \mathrm{mL}^{-1}$; Sigma) and fibronectin $\left(50 \mu \mathrm{g} \mathrm{m} \mathrm{m}^{-1}\right.$; Sigma) and cultured for two more days prior to performing permeability experiments [19]. Characterization of the BC1-hBMEC cells has been reported elsewhere [19].

\section{Permeability measurements \\ 2-PAM}

MDCK cells were seeded on transwells (24 well; PE; $0.33 \mathrm{~cm}^{2}$ area; $0.4 \mu \mathrm{m}$ pore diameter, Corning, Corning, NY, USA) coated with collagen I (rat tail, $10 \mu \mathrm{g} \mathrm{cm}^{-2}$, Corning) at a density of $6 \times 10^{5}$ cells $\mathrm{cm}^{-2}$. Permeability experiments were performed 4 days after seeding. The medium was changed $2 \mathrm{~h}$ before the experiment and transepithelial electrical resistance (TEER) was measured before all experiments (Endohm/EVOM2). For MDCK cells, permeability measurements were performed if the TEER was $\geq 90 \Omega \mathrm{cm}^{2}$ (see Additional file 1: Table S1: TEER values for transwell experiments) [24, 25]. To confirm the integrity of the MDCK monolayers, the permeability of Lucifer yellow, $100 \mu \mathrm{M}$, was measured for up to $2 \mathrm{~h}$. In all cases the permeability was $\leq 1 \times 10^{-6} \mathrm{~cm} \mathrm{~s}^{-1}$ : $0.71 \pm 0.34 \times 10^{-6} \mathrm{~cm} \mathrm{~s}^{-1}$ (MDCKII), $0.38 \pm 0.20 \times 10^{-6}$ $\mathrm{cm} \mathrm{s}^{-1}$ (MDCKII-MDR1), and $0.46 \pm 0.21 \times 10^{-6} \mathrm{~cm} \mathrm{~s}^{-1}$ (MDCKII-FLuc-ABCG2). The measured permeability for Lucifer yellow under the same conditions in transwells without cells, was $4.35 \times 10^{-5} \mathrm{~cm} \mathrm{~s}^{-1}$.

All experiments with MDCK cells were performed in Hank's balanced salt solution (HBSS) with $10 \mathrm{mM}$ HEPES (Sigma) and $15 \mathrm{mM}$ glucose (Sigma), pH 7.4. After incubation in media for $2 \mathrm{~h}$, cell monolayers were immersed in fresh HBSS for 30 min to remove any traces of media. Then $100 \mu \mathrm{M}$ or $10 \mu \mathrm{M}$ 2-PAM (pralidoxime chloride, Sigma) in HBSS was pipetted into either the apical or basolateral chamber, with HBSS on the receiving side. Cell monolayers with test solutes were incubated at $37^{\circ} \mathrm{C}$ with $5 \% \mathrm{CO}_{2}$ on a rocker to ensure good mixing.

For experiments with BC1-hBMECs, cells were seeded on transwells (24 well; PE; $0.33 \mathrm{~cm}^{2}$ area; $0.4 \mu \mathrm{m}$ pore diameter, Corning) coated overnight with a 50/50 mixture collagen IV $\left(100 \mu \mathrm{g} \mathrm{mL}^{-1}\right.$; Sigma) and fibronectin $\left(50 \mu \mathrm{g} \mathrm{mL}^{-1}\right.$; Sigma) at a density of $1 \times 10^{6}$ cells $\mathrm{mL}^{-1}$. For BC1-hBMECs, permeability measurements were performed with cells that had a TEER of $\geq 1500 \Omega \mathrm{cm}^{2}$. Experiments were performed in transport buffer (distilled Millipore water with $0.12 \mathrm{M} \mathrm{NaCl}, 25 \mathrm{mM} \mathrm{NaHCO}$, $3 \mathrm{mM} \mathrm{KCl}, 2 \mathrm{mM} \mathrm{MgSO}_{4}, 2 \mathrm{mM} \mathrm{CaCl} 2,0.4 \mathrm{mM} \mathrm{K}_{2} \mathrm{HPO}_{4}$, 
$1 \mathrm{mM}$ HEPES, and $0.1 \%$ human platelet poor-derived serum) without the pre-incubation of media or rocking of the cells. After 2 days in EC media, $100 \mu \mathrm{M}$ of 2-PAM in transport buffer was pipetted into the apical or basolateral well with transport buffer on the receiving side.

The concentration of 2-PAM was determined by HPLC (1260 Infinity HPLC, Agilent, Santa Clara, CA, USA) with UV Vis detection at $296 \mathrm{~nm}$. Solvents were degassed by sonication for $45 \mathrm{~min}$ before use and all samples were run at room temperature. An isocratic flow of 44 vol.\% acetonitrile (HPLC grade, Chromasolv, Sigma) and 56 vol.\% ammonium acetate (0.03 M; HPLC grade, Sigma), pH 4.5, was used with a PolyCAT A column $(100 \times 2.1 \mathrm{~mm}, 5 \mu \mathrm{M}, 300 \AA$, 102CT05-03, Poly LC Inc, Columbia, MD, USA) [26]. Calibration curves were constructed from standard solutions with concentrations of $0.1,1,10$ and $100 \mu \mathrm{M}$. Due to the simplicity of the procedure, no internal standard was used.

\section{2-PAM/atropine}

To assess whether atropine, which is often co-administered with 2-PAM, modulates the transport of 2-PAM we performed experiments where MDCK cells were pretreated with atropine. After $2 \mathrm{~h}$ incubation in media, and 30 min rinse in HBSS, MDCKII monolayers were pretreated with $1 \mu \mathrm{M}$ atropine for $30 \mathrm{~min}$, rinsed in HBSS for $5 \mathrm{~min}$, and then incubated in $100 \mu \mathrm{M}$ 2-PAM for permeability measurements using the same procedure as described above. 2-PAM concentrations were measured by HPLC with an isocratic flow of 55 vol.\% acetonitrile and 45 vol.\% ammonium acetate $(0.03 \mathrm{M})$.

\section{Rhodamine 123}

To confirm the up-regulation and polarization of P-gp efflux pumps to the apical face, we measured the permeability of Rhodamine 123, a known P-gp substrate, across MDCKII and MDCKII. MDR1 monolayers [27]. Permeability experiments were performed for $60 \mathrm{~min}$ at a concentration of $50 \mu \mathrm{M}$. The concentration of Rhodamine 123 (excitation 486 and emission 523) was measured by fluorescence (Fluorolog, Horiba Scientific, Edison, NJ, USA). Calibration curves were generated over the concentration range from 0.001 to $1 \mu \mathrm{M}$.

\section{Coupled permeability and acetylcholinesterase reactivation}

To assess coupled 2-PAM transport and enzyme reactivation, experiments were performed in a transwell device with acetylcholinesterase in the basolateral chamber. Confluent monolayers of MDCKII cells were formed as described above. Electric eel acetylcholinesterase (AChE, $1 \mathrm{U}$ or about $1 \mu \mathrm{L},>1000 \mathrm{U} / \mathrm{mg}$, Sigma) was placed into the basolateral chamber ( 24 well plate). A mixture of Ellman's reagent (DTNB), final concentration $300 \mu \mathrm{M}$, and acetylthiocholine (ASCh), final concentration $450 \mu \mathrm{M}$, dissolved in HBSS, was introduced into the basolateral chamber, to give a final volume of $600 \mu \mathrm{L}$. The time-dependent activity of the enzyme was determined from the absorbance of the DTNB reporter at $412 \mathrm{~nm}$ using a plate reader (Spectramax M3). Results were normalized to the activity of the uninhibited enzyme, unnormalized data are provided in the Additional file 1 (Figure S1: Non-normalized reactivation data).

Inhibition was achieved by incubating the enzyme with $0.72 \mathrm{mM}$ parathion (PESTANAL-grade, Sigma) or $4.6 \mu \mathrm{M}$ paraoxon (PESTANAL-grade, Sigma) for $20 \mathrm{~min}$ prior to experiments. In inhibition experiments, the enzyme was inhibited with parathion. Paraoxon, a metabolite of parathion, is about three orders of magnitude more potent as an anticholinesterase inhibitor [28]. The parathion concentration was 157-fold higher than the paraoxon concentration, reflecting their different activities. For reactivation experiments, 2-PAM was introduced into either the apical or basolateral chamber in HBSS. Introducing 2-PAM into the basolateral chamber simulates reactivation alone, whereas introduction of 2-PAM into the apical chamber simulates coupled trans-endothelial transport and reactivation.

\section{Positive control (uninhibited enzyme + substrate)}

To assess the kinetics of enzyme interaction with the substrate, uninhibited enzyme (AChE), along with substrate (ASCh), and reporter (DTNB) in HBSS were introduced into the basolateral chamber. An apical transwell chamber with a monolayer of MDCK cells was located on the top of the basolateral chamber to ensure that the control was performed in the same way as the other experiments.

\section{Negative control (inhibited enzyme + substrate)}

To assess the efficiency of enzyme inhibition, $\mathrm{AChE}$ was mixed for $20 \mathrm{~min}$ with concentrated parathion $(0.72 \mathrm{mM}$ final concentration) or paraoxon $(4.6 \mu \mathrm{M}$ final concentration) organophosphates (OP). The inhibited enzyme (AChE-OP) was then placed in the basolateral chamber with substrate (ASCh) and reporter (DTNB) in HBSS. An apical transwell chamber was located on the top of the basolateral chamber as described above.

\section{Direct interaction of 2-PAM (inhibited}

enzyme + substrate + reactivator)

To assess the kinetics of direct reactivation of inhibited enzyme, $100 \mu \mathrm{M}$ 2-PAM was introduced in the basolateral chamber with the inhibited enzyme (AChE-OP), substrate (ASCh) and reporter (DTNB) in HBSS. An apical transwell chamber was located on the top of the basolateral chamber as described above. 


\section{Coupled transport of 2-PAM and reactivation}

To evaluate the coupled transport of 2-PAM across a cell monolayer and reactivation of inhibited enzyme, $100 \mu \mathrm{M}$ of 2-PAM was introduced into the apical chamber, with inhibited enzyme (AChE-OP), reporter (DTNB), and substrate $(\mathrm{ASCH})$ in the basolateral chamber.

\section{Statistics}

Permeability, activity, and reactivation half-time represent the mean \pm standard deviation. Statistical significance was determined using a student's $t$ test (two-tailed with unequal variance) with $p<0.01^{* * *}$ and $p<0.001^{* * * *}$. The average permeability values for the MDCK cell lines were calculated from analysis of all of the replicates. Due to variations between differentiations, the average permeability across the BC1-hBMECs was calculated from the average values from each differentiation. Similarly, the efflux ratio was calculated from the average value obtained from each differentiation.

\section{Results}

\section{Permeability of 2-PAM}

To assess the transport of 2-PAM and to determine whether 2-PAM is an efflux pump substrate, transwell experiments were performed in three cell lines: MDCKII, MDCKII-MDR1, MDCKII-FLuc-ABCG2 at concentrations of 10 and $100 \mu \mathrm{M}$ (Table 1; Fig. 1). In $10 \mu \mathrm{M}$ 2-PAM, the average apical-to-basolateral permeability in MDCKII and MDCKII-MDR1 monolayers was about $2 \times 10^{-6} \mathrm{~cm} \mathrm{~s}^{-1}$. The average permeability of MDCKIIABCG2 monolayers was slightly lower, $0.83 \times 10^{-6}$ $\mathrm{cm} \mathrm{s}^{-1}$, although the difference compared to the MDCKII and MDCKII-MDR1 monolayers was not significant. For $100 \mu \mathrm{M}$ 2-PAM, the average permeability in MDCKII and MDCKII-MDR1 monolayers increased to about $3 \times 10^{-6} \mathrm{~cm} \mathrm{~s}^{-1}$; this increase was significant in MDCKII cells $(p=0.05)$, but not significant in MDCKII-MDR1 cells. The average permeability in MDCKII-ABCG2 cells was $0.76 \times 10^{-6} \mathrm{~cm} \mathrm{~s}^{-1}$, very close to the value in $10 \mu \mathrm{M}$ 2-PAM. The average basolateral-to-apical permeability was very close to the apical-to-basolateral value in all three cell lines with no statistical difference. The apical-to-basolateral permeability of 2-PAM across the stem-cell derived BC1-hBMECs was $1.12 \pm 0.80 \times 10^{-6}$ $\mathrm{cm} \mathrm{s} \mathrm{s}^{-1}$, comparable to the permeability across the MDCKII cells. The basolateral-to-apical permeability $\left(0.49 \pm 0.16 \times 10^{-6} \mathrm{~cm} \mathrm{~s}^{-1}\right)$ was lower $(p=0.05)$.

\section{Influence of atropine on 2-PAM permeability}

To determine whether atropine, co-administered with 2-PAM, modulates the permeability of 2-PAM, we measured the permeability of 2-PAM following pretreatment of the MDCKII monolayer with atropine. The
Table 1 Permeability of pralidoxime (2-PAM), rhodamine $123 \mathrm{R} 123$ ) and Lucifer yellow (Ly) across MDCKII, MDCKIIMDR1, MDCKII-FLuc-ABCG2, and BC1-hBMEC monolayers

\begin{tabular}{|c|c|c|c|c|c|}
\hline & $P_{\text {app }} A \rightarrow B\left(\mathrm{~cm} \mathrm{~s}^{-1}\right)$ & $\mathbf{N}$ & $P_{\text {app }} B \rightarrow A\left(\mathrm{~cm} \mathrm{~s}^{-1}\right)$ & $\mathbf{N}$ & $\begin{array}{l}\text { Efflux } \\
\text { ratio }\end{array}$ \\
\hline \multicolumn{6}{|l|}{$100 \mu M$ 2-PAM } \\
\hline MDCKII & $2.99 \pm 1.12 \times 10^{-6}$ & 11 & $2.48 \pm 1.30 \times 10^{-6}$ & 8 & 0.82 \\
\hline MDCKII-MDR1 & $3.01 \pm 1.27 \times 10^{-6}$ & 8 & $2.51 \pm 1.08 \times 10^{-6}$ & 7 & 0.83 \\
\hline $\begin{array}{l}\text { MDCKII-FLuc- } \\
\text { ABCG2 }\end{array}$ & $0.76 \pm 0.05 \times 10^{-6}$ & 7 & $0.98 \pm 0.40 \times 10^{-6}$ & 7 & 1.30 \\
\hline BC1-hBMECs & $\begin{array}{l}1.12 \pm 0.80 \times 10^{-6} \\
(n=5)\end{array}$ & 18 & $\begin{array}{l}0.49 \pm 0.16 \times 10^{-6} \\
(n=3)\end{array}$ & 12 & 0.84 \\
\hline \multicolumn{6}{|l|}{$10 \mu M$ 2-PAM } \\
\hline MDCKII & $1.62 \pm 0.21 \times 10^{-6}$ & 6 & $1.29 \pm 1.76 \times 10^{-6}$ & 7 & 0.80 \\
\hline MDCKII-MDR1 & $2.03 \pm 0.14 \times 10^{-6}$ & 8 & $1.18 \pm 0.45 \times 10^{-6}$ & 8 & 0.58 \\
\hline $\begin{array}{l}\text { MDCKII-FLuc- } \\
\text { ABCG2 }\end{array}$ & $0.83 \pm 0.35 \times 10^{-6}$ & 7 & $0.99 \pm 0.62 \times 10^{-6}$ & 7 & 1.18 \\
\hline \multicolumn{6}{|l|}{$50 \mu M R 123$} \\
\hline MDCKII & $0.30 \pm 0.20 \times 10^{-6}$ & 6 & $3.18 \pm 0.60 \times 10^{-6}$ & 5 & 10.7 \\
\hline MDCKII-MDR1 & $0.21 \pm 0.21 \times 10^{-6}$ & 12 & $4.36 \pm 0.41 \times 10^{-6}$ & 11 & 20.3 \\
\hline \multicolumn{6}{|l|}{$100 \mu M L Y$} \\
\hline MDCKII & $0.71 \pm 0.34 \times 10^{-6}$ & 7 & & & \\
\hline MDCKII-MDR1 & $0.38 \pm 0.20 \times 10^{-6}$ & 7 & & & \\
\hline $\begin{array}{l}\text { MDCKII-FLuc- } \\
\text { ABCG2 }\end{array}$ & $0.46 \pm 0.21 \times 10^{-6}$ & 8 & & & \\
\hline \multicolumn{6}{|l|}{ 2-PAM atropine } \\
\hline MDCKII & $2.54 \pm 0.33 \times 10^{-6}$ & 7 & & & \\
\hline
\end{tabular}

$A \rightarrow B$ represents apical-to-basolateral permeability, and $B \rightarrow A$ represents basolateral-to-apical permeability. Permeability values are reported as mean \pm standard deviation. The efflux ratio is the ratio of basolateral-to-apical permeability divided by the apical-to-basolateral permeability. For MDCK cells, permeabilities and efflux ratios were calculated from the total number of replicates $(\mathrm{N})$. Data were obtained from at least three independent experiments each with two or more replicates. For the BC1-hBMECs, the permeabilities and efflux ratios were calculated from the average of each differentiation, where $\mathrm{N}$ represents the number of independent differentiations

permeability of 2-PAM was $2.54 \pm 0.33 \times 10^{-6} \mathrm{~cm} \mathrm{~s}^{-1}$, which was not significantly different to the value of $2.99 \pm 1.12 \times 10^{-6} \mathrm{~cm} \mathrm{~s}^{-1}$ obtained without pre-treatment with atropine (Table 1).

\section{Permeability of rhodamine 123}

To confirm the polarization of the P-gp efflux pumps to the apical surface of the MDCK cells, we measured the permeability of $50 \mu \mathrm{M}$ rhodamine 123 , a known substrate for the P-gp efflux pump [27, 29], in MDCKII and MDCKII-MDR1 cells (Table 1). The basolateral-toapical permeability of rhodamine 123 in MDCKII was $3.18 \times 10^{-6} \mathrm{~cm} \mathrm{~s}^{-1}$, with an apical-to-basolateral permeability of $0.30 \times 10^{-6} \mathrm{~cm} \mathrm{~s}^{-1}(p=0.001)$, corresponding to an efflux ratio of 10.7. For the MDCKII-MDR1 cells, the basolateral-to-apical permeability was $4.36 \times 10^{-6}$ $\mathrm{cm} \mathrm{s} \mathrm{s}^{-1}$, with an apical-to-basolateral permeability of $0.22 \times 10^{-6} \mathrm{~cm} \mathrm{~s}^{-1}(p=0.001)$ corresponding to an efflux ratio of 20.3. The basolateral-to-apical permeabilities to 

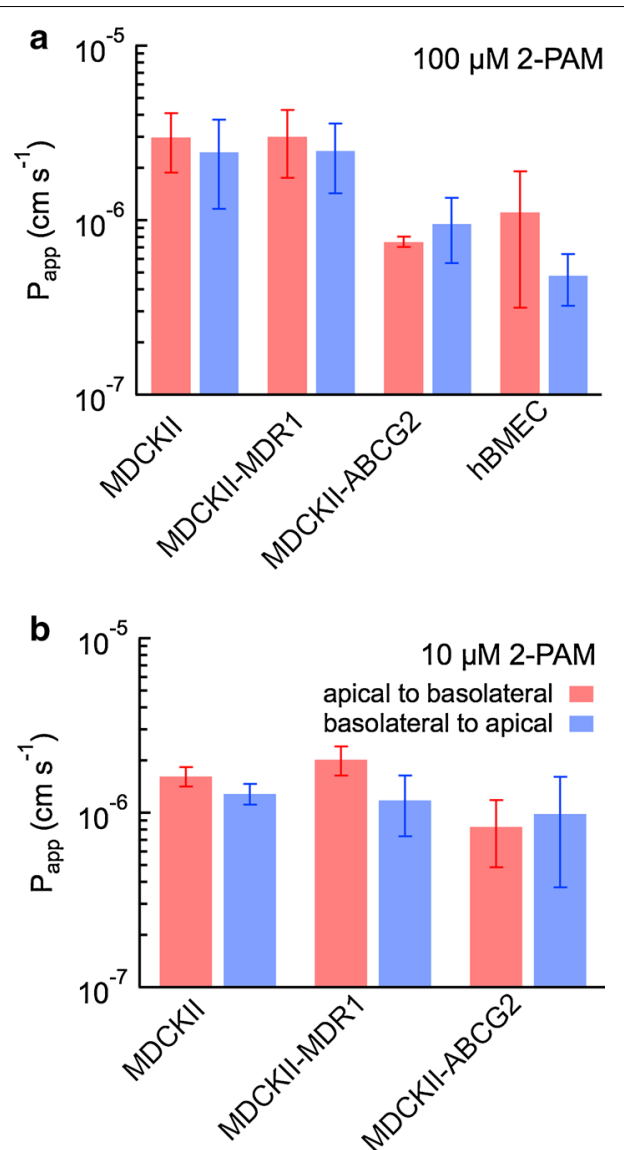

Fig. 1 a 2-PAM permeability in four different cells lines at a concentration of $100 \mu \mathrm{M}$. b 2-PAM permeability of in three different cells lines at a concentration of $10 \mu \mathrm{M}$. Basolateral-to-apical (red), basolateral-toapical (blue). Permeability is reported as mean \pm standard deviation. Experiments were performed in HBSS (MDCKII, MDCKII-MDR1, MDCKII-ABCG2) or transport buffer (BC1-hBMEC)

rhodamine in MDCKII and MDCKII. MDR1 cells were significantly different $(p=0.02)$ supporting upregulation and polarization of P-gp efflux pumps to the apical side of the MDCKII.MDR1 cells. Apical-to-basolateral permeabilities of $0.83 \times 10^{-6}$ and $0.89 \times 10^{-6} \mathrm{~cm} \mathrm{~s}^{-1}$, with corresponding efflux ratios of 9 and 115, have been reported for transport of $5 \mu \mathrm{M}$ rhodamine 123 across MDCKII. MDR1 cells $[27,29]$. The reported efflux ratio for rhodamine in BC1-hBMEC cells is approximately 4 [19].

\section{Coupled transport and acetylcholinesterase (AChE) reactivation}

To assess the coupled transcellular transport and AChE reactivation, we performed transwell experiments with a monolayer of MDCKII cells and inhibited enzyme in the basolateral chamber (Fig. 2a). Acetylcholinesterase was inhibited with an organophosphate (parathion or paraoxon) for $20 \mathrm{~min}$ and then introduced into the basolateral chamber of a transwell device, along with acetylthiocholine (ASCh) and the colorimetric reporter (DTNB). Control experiments were performed to confirm the activity of the enzyme and effectiveness of the inhibitor.

In the absence of 2-PAM, the activity of the inhibited enzyme (AChE-OP) increased very slowly during the $2 \mathrm{~h}$ experiment (Fig. 2b). When 2-PAM was introduced into the basolateral chamber with inhibited enzyme, reactivation occurred much more quickly (Parathion: inhibited enzyme and direct reactivation $p<0.001$, Paraoxon: inhibited enzyme and direct reactivation $p<0.01$ ). However, when 2-PAM was introduced into the apical chamber, reactivation of the inhibited enzyme was slowed considerably due to the coupled transport and reactivation (Parathion: direct reactivation and transport reactivation $p<0.001$, paraoxon: direct reactivation and transport reactivation $p<0.01$ ).

The activity of the enzyme following transcellular transport of 2-PAM across MDCKII monolayers $\left(3.49 \times 10^{-4} \mathrm{abs} \mathrm{s}^{-1}\right)$ was about four fold lower than when the inhibited enzyme was directly exposed to 2-PAM $\left(1.35 \times 10^{-3} \mathrm{abs} \mathrm{s}^{-1}\right)$ (Fig. 2c). Similarly, the halftime for reactivation of the substrate increased sixfold from $680 \mathrm{~s}$ for direct reactivation to $4100 \mathrm{~s}$ following transcellular transport (Fig. 2d).

\section{Discussion}

\section{Transendothelial transport}

The permeability of 2-PAM was between $1 \times 10^{-6}$ and $2 \times 10^{-6} \mathrm{~cm} \mathrm{~s}^{-1}$ in all three MDCK cell lines, lower than for most central nervous system drugs, which typically have permeabilities greater than $1 \times 10^{-5} \mathrm{~cm} \mathrm{~s}^{-1}$ [30]. However several CNS drugs have permeabilities similar to 2-PAM, including the antipsychotics perphenazine $\left(p=1.8 \times 10^{-6} \mathrm{~cm} \mathrm{~s}^{-1}\right)$ and fluphenazine $\left(p=3.5 \times 10^{-6} \mathrm{~cm} \mathrm{~s}^{-1}\right)$, the anti-anxiety drug sertralin (Zoloft) $\left(p=2.1 \times 10^{-6} \mathrm{~cm} \mathrm{~s}^{-1}\right)$, and the analgesic, morphine $\left(p=2 \times 10^{-6} \mathrm{~cm} \mathrm{~s}^{-1}\right)$ [16]. While morphine has a low permeability in MDCK cells, the therapeutic dose is particularly low [16]. The low permeability of 2-PAM explains the reported low concentration in the brain in animal studies [10] and the recommended sustained clinical infusion in a clinical setting [6].

MDCK cells are widely used to assess brain penetration of small molecules. Although MDCK cell lines are epithelial in origin and not human, they express tight junction proteins, which limit paracellular transport. Variants such as MDCKII-MDR1 can be used to determine whether a solute is an efflux pump substrate. The stem cell derived BC1-hBMECs exhibit high transendothelial electrical resistance (TEER $>1000 \Omega \mathrm{cm}^{2}$ ), low permeability to solutes such as Lucifer yellow, and 


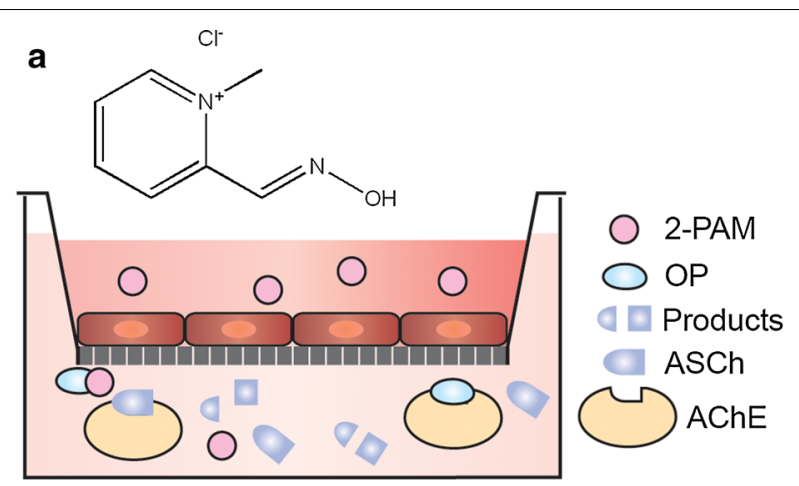

C
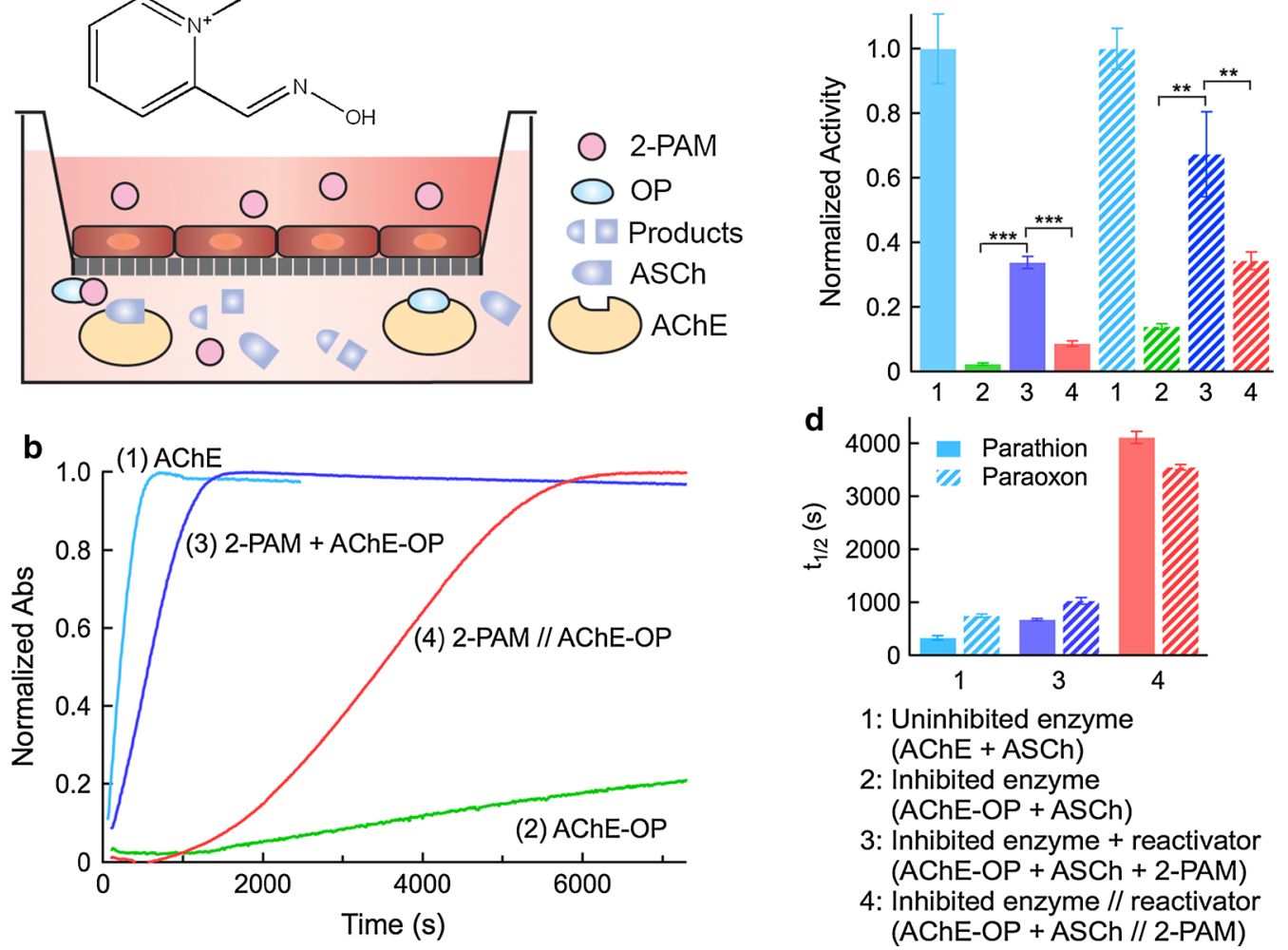

Fig. 2 a Schematic illustration of the modified transwell assay for measurement of coupled transcellular transport and enzymatic activity, and the chemical structure of 2-PAM. b Representative normalized absorbance versus time plots for reactivation of AChE. 1 AChE + ASCh: positive control (uninhibited enzyme + substrate). 2 AChE-OP + ASCh: negative control (inhibited enzyme + substrate). 3 AChE-OP + ASCh + 2-PAM: reactivation with no transport (inhibited enzyme + substrate + reactivator). 4 2-PAM//AChE-OP + ASCh: transcellular transport + reactivation. c Normalized AChE activity ( $\mathrm{dA} / \mathrm{dt}$ ) obtained from absorbance versus time curves at the inflection point. The legend provides the details of each experiment. d Half-time for AChE reactivation. Data represent mean \pm SD. All reactivation experiments were performed in HBSS

express tight junction proteins (e.g. claudin-5), transporters (e.g. LAT-1), and efflux pumps (e.g. P-gp) [17, 19]. The permeability of the stem cell derived BC1-hBMECs $\left(p=1.12 \pm 0.80 \times 10^{-6} \mathrm{~cm} \mathrm{~s}^{-1}\right)$ was slightly lower than values obtained in MDCK cells, but in the range that is consistent with slow accumulation in the brain.

High permeability values are usually associated with small molecular weight and moderate lipophilicity [31, 32]. While 2-PAM has a molecular weight under $500 \mathrm{Da}$ $(172 \mathrm{Da})$, fewer than 5 hydrogen bond donors (1), and fewer than 10 hydrogen bond acceptors (2), the charge results in a low lipophilicity and hence 2-PAM is not expected to have a high permeability.

There was no significant difference between apical-andbasolateral and basolateral-to-apical permeabilities in MDCK cells, indicating that 2-PAM is not a substrate of the P-gp or ABCG2 pumps. To confirm the polarized expression and activity of the P-gp efflux pumps, we determined efflux ratios of 10.7 and 20.3 for the MDCKII and MDCKII. MDR1 cell lines for the known P-gp substrate rhodamine 123.

Treatment for organophosphate poisoning involves co-administration of 2-PAM and atropine. The permeability of 2-PAM was the same in MDCKII cells and cells pretreated with atropine, showing that atropine does not modulate the permeability of 2-PAM.

\section{Coupled transcellular transport and enzyme reactivation}

To study coupled transcellular transport of the neurotoxin antidote 2-PAM with enzyme reactivation, we developed a modified transwell assay with inhibited enzyme (AChE-OP), substrate (ASCh), and reporter (DTNB) in the basolateral chamber. When 2-PAM was introduced into the apical chamber of the transwell device, the activity of the enzyme decreased four fold compared to the case where 2-PAM was introduced directly into the basolateral chamber. Similarly, the halftime for reactivation of the enzyme increased six fold 
when coupled to transcellular transport. These results highlight the difficulty in maintaining a therapeutic dose when the permeability is low.

\section{Conclusions}

The permeability of the nerve agent reactivator 2-PAM is $1 \times 10^{-6}-2 \times 10^{-6} \mathrm{~cm} \mathrm{~s}^{-1}$ and is not influenced by pre-treatment with atropine. In addition, 2-PAM is not a substrate for the P-gp or BCRP/ABCG2 efflux pumps. Similar permeability values were obtained for human brain microvascular endothelial cells derived from induced pluripotent stem cells. In a modified transwell assay to couple transcellular transport and enzyme reactivation, we showed that transcellular transport decreased enzymatic activity four fold and increased the reactivation half-time six fold. The low permeability explains poor brain penetration of 2-PAM and the necessity for sustained IV infusion in response to organophosphate poisoning.

\section{Additional file}

Additional file 1. Table S1.

\begin{abstract}
Abbreviations
MDCK: Madin-Darby canine kidney epithelial cells; 2-PAM: pralidoxime chloride; $B C 1$-hBMEC: stem cell derived human brain microvascular endothelial cells; TEER: transendothelial electrical resistance; MDR1: multi-drug resistance gene; P-gp: P-glycoprotein; ABCG2: ATP-binding cassette sub-family G member 2; BCRP: breast cancer resistance protein; ASCh: acetylthiocholine; AChE: acetylcholinesterase; AChE-OP: inhibited enzyme; DTNB: 5,5'-dithiobis(2-nitrobenzoic acid) (Ellman's reagent)
\end{abstract}

\section{Authors' contributions}

EG performed the experiments. EG and PS analyzed the data. EG, IM, JC, and PS wrote the manuscript. All authors read and approved the final manuscript.

\section{Author details}

${ }^{1}$ Institute for Nanobiotechnology Johns Hopkins University, 3400 North Charles Street, Baltimore, MD 21218, USA. ${ }^{2}$ Department of Materials Science and Engineering, Johns Hopkins University, 3400 North Charles Street, Baltimore, MD 21218, USA. ${ }^{3}$ Department of Radiology and Radiological Science, Johns Hopkins University, 3400 North Charles Street, Baltimore, MD 21231, USA. ${ }^{4}$ College of Veterinary Medicine, Mississippi State University, Mississippi State, MS 39762-6100, USA

\section{Acknowledgements}

The authors gratefully acknowledge support from DTRA (HDTRA1-15-1-0046).

\section{Competing interests}

The authors declare that they have no competing interests.

Received: 19 March 2016 Accepted: 8 June 2016

Published online: 11 July 2016

\section{References}

1. Pardridge WM. Drug transport across the blood-brain barrier. J Cereb Blood Flow Metab. 2012;32(11):1959-72. doi:10.1038/jcbfm.2012.126.
2. Salinas S, Schiavo G, Kremer EJ. A Hitchhiker's guide to the nervous system: the complex journey of viruses and toxins. Nat Rev Microbiol. 2010;8(9):645-55. doi:10.1038/nrmicro2395.

3. Abbott NJ, Ronnback L, Hansson E. Astrocyte-endothelial interactions at the blood-brain barrier. Nat Rev Neurosci. 2006;7(1):41-53. doi:10.1038/ nrn1824

4. Dando SJ, Mackay-Sim A, Norton R, Currie BJ, St John JA, Ekberg JA, et al. Pathogens penetrating the central nervous system: infection pathways and the cellular and molecular mechanisms of invasion. Clin Microbiol Rev. 2014;27(4):691-726. doi:10.1128/CMR.00118-13.

5. Colovic MB, Krstic DZ, Lazarevic-Pasti TD, Bondzic AM, Vasic VM. Acetylcholinesterase inhibitors: pharmacology and toxicology. Curr Neuropharmacol. 2013;11(3):315-35. doi:10.2174/1570159X11311030006.

6. Holstege CP, Dobmeier SG. Nerve agent toxicity and treatment. Curr Treat Options Neurol. 2005;7(2):91-8. doi:10.1007/s11940-005-0018-y.

7. Wiener SW, Hoffman RS. Nerve agents: a comprehensive review. J Intensive Care Med. 2004;19(1):22-37. doi:10.1177/0885066603258659.

8. FDA. PROTOPAM Chloride (pralidoxime chloride) for injection. New Drug Application (NDA): U.S. Food and Drug Administration 2010 September 8, 2010 Contract No: : 014134/S-022.

9. Kassa J. Review of oximes in the antidotal treatment of poisoning by organophosphorus nerve agents. J Toxicol Clin Toxic 2002;40(6):803-16.

10. Lorke DE, Nurulain SM, Hasan MY, Kuca K, Musilek K, Petroianu GA. Eight new bispyridinium oximes in comparison with the conventional oximes pralidoxime and obidoxime: in vivo efficacy to protect from diisopropylfluorophosphate toxicity. J Appl Toxicol. 2008;28(7):920-8. doi:10.1002/ jat.1359.

11. Medicis JJ, Stork CM, Howland MA, Hoffman RS, Goldfrank LR. Pharmacokinetics following a loading plus a continuous infusion of pralidoxime compared with the traditional short infusion regimen in human volunteers. J Toxicol Clin Toxic. 1996;34(3):289-95.

12. Abbara C, Rousseau JM, Lelievre B, Turcant A, Lallement G, Ferec S, et al. Pharmacokinetic analysis of pralidoxime after its intramuscular injection alone or in combination with atropine-avizafone in healthy volunteers. $\mathrm{Br}$ J Pharmacol. 2010;161(8):1857-67. doi:10.1111/j.1476-5381.2010.01007.x.

13. Jovanovic D. Pharmacokinetics of pralidoxime chloride: a comparative study in healthy volunteers and in organophosphorus poisoning. Arch Toxicol. 1989;63(5):416-8.

14. Willems JL, Debisschop HC, Verstraete AG, Declerck C, Christiaens Y, Vanscheeuwyck $P$, et al. Cholinesterase reactivation in organophosphorus poisoned patients depends on the plasma-concentrations of the oxime pralidoxime methylsulfate and of the organophosphate. Arch Toxicol. 1993:67(2):79-84 doi:10.1007/Bf01973675.

15. Schexnayder S, James LP, Kearns GL, Farrar HC. The pharmacokinetics of continuous infusion pralidoxime in children with organophosphate poisoning. J Toxicol Clin Toxic. 1998;36(6):549-55.

16. Summerfield SG, Read K, Begley DJ, Obradovic T, Hidalgo IJ, Coggon S, et al. Central nervous system drug disposition: the relationship between in situ brain permeability and brain free fraction. J Pharmacol Exp Ther. 2007;322(1):205-13. doi:10.1124/jpet.107.121525.

17. Lippmann ES, Azarin SM, Kay JE, Nessler RA, Wilson HK, Al-Ahmad A, et al. Derivation of blood-brain barrier endothelial cells from human pluripotent stem cells. Nat Biotechnol. 2012;30(8):783-91. doi:10.1038/ nbt.2247.

18. Lippmann ES, Al-Ahmad A, Azarin SM, Palecek SP, Shusta EV. A retinoic acid-enhanced, multicellular human blood-brain barrier model derived from stem cell sources. Sci Rep. 2014;4:4160. doi:10.1038/srep04160.

19. Katt ME, Xu ZS, Gerecht S, Searson PC. Human brain microvascular endothelial cells derived from the BC1 iPS cell line exhibit a blood-brain barrier phenotype. PLOS ONE. 2016;11(4):e0152105. doi:10.1371/journal. pone.0152105.

20. Evers R, Kool M, Smith AJ, Van Deemter L, De Haas M, Borst P. Inhibitory effect of the reversal agents V-104, GF120918 and Pluronic L61 on MDR1 Pgp-, MRP1- and MRP2-mediated transport. Br J Cancer. 2000;83(3):36674. doi:10.1054/bjoc.2000.1260.

21. Zhang YM, Bressler JP, Neal J, Lal B, Bhang HEC, Laterra J, et al. ABCG2/ BCRP expression modulates D-luciferin-based bioluminescence imaging Cancer Res. 2007;67(19):9389-97. doi:10.1158/0008-5472.CAN-07-0944. 
22. Zhang Y, Byun Y, Ren YR, Liu JO, Laterra J, Pomper MG. Identification of inhibitors of ABCG2 by a bioluminescence imaging-based high-throughput assay. Cancer Res. 2009;69(14):5867-75. doi:10.1158/0008-5472. CAN-08-4866.

23. Chou BK, Mali P, Huang X, Ye Z, Dowey SN, Resar LM, et al. Efficient human iPS cell derivation by a non-integrating plasmid from blood cells with unique epigenetic and gene expression signatures. Cell Res. 2011;21(3):518-29. doi:10.1038/cr.2011.12.

24. Dukes JD, Whitley P, Chalmers AD. The MDCK variety pack: choosing the right strain. Bmc Cell Biol. 2011;12:1. doi:10.1186/1471-2121-12-43.

25. Avdeef A, Deli MA, Neuhaus W. In vitro assays for assessing BBB permeability: artificial membrane and cell culture models. In: Di L, Kerns EH, editors. Blood-brain barrier in drug discovery: optimizing brain exposure of CNS drugs and minimizing brain side effects for peripheral drugs. New York: Wiley; 2015. p. 188-237.

26. Singh H, Moorad-Doctor D, Ratcliffe RH, Wachtel K, Castillo A, Garcia GE. A rapid cation-exchange HPLC method for detection and quantification of pyridinium oximes in plasma and tissue. J Anal Toxicol. 2007;31(2):69-74.

27. Tang F, Ouyang H, Yang JZ, Borchardt RT. Bidirectional transport of rhodamine 123 and Hoechst 33342, fluorescence probes of the binding sites on P-glycoprotein, across MDCK-MDR1 cell monolayers. J Pharm Sci. 2004;93(5):1185-94. doi:10.1002/jps.20046.
28. Monnet-Tschudi F, Zurich M-G, Schilter B, Costa LG, Honegger P. Maturation-dependent effects of chlorpyrifos and parathion and their oxygen analogs on acetylcholinesterase and neuronal and glial markers in aggregating brain cell cultures. Toxicol Appl Pharm. 2000;165(3):175-83. doi:10.1006/taap.2000.8934

29. Wang Q, Rager JD, Weinstein K, Kardos PS, Dobson GL, Li J, et al. Evaluation of the MDR-MDCK cell line as a permeability screen for the blood-brain barrier. Int J Pharm. 2005;288(2):349-59. doi:10.1016/j. ijpharm.2004.10.007.

30. Wong AD, Ye M, Levy AF, Rothstein JD, Bergles DE, Searson PC. The bloodbrain barrier: an engineering perspective. Front Neuroeng. 2013;6:7. doi:10.3389/fneng.2013.00007.

31. Lipinski CA, Lombardo F, Dominy BW, Feeney PJ. Experimental and computational approaches to estimate solubility and permeability in drug discovery and development settings. Adv Drug Deliv Rev. 2001;46(1-3):3-26.

32. Leeson P. Drug discovery: chemical beauty contest. Nature. 2012:481(7382):455-6. doi:10.1038/481455a.

\section{Submit your next manuscript to BioMed Central and we will help you at every step:}

- We accept pre-submission inquiries

- Our selector tool helps you to find the most relevant journal

- We provide round the clock customer support

- Convenient online submission

- Thorough peer review

- Inclusion in PubMed and all major indexing services

- Maximum visibility for your research

Submit your manuscript at www.biomedcentral com/submit 